Care: Jurnal Ilmiah Ilmu Kesehatan Vol.8, No.3, 2020, hal 396-407

Tersedia online di https://jurnal.unitri.ac.id/index.php/care

ISSN 2527-8487 (online)

ISSN 2089-4503 (cetak)

\title{
OPTIMALISASI POSISI JANIN MELALUI PRENATAL YOGA TERHADAP OUTPUT PERSALINAN DI PUSKESMAS WILAYAH KOTA CIREBON
}

\author{
Nurasih $^{1)}$, Endang Nurrochmi ${ }^{2}$ \\ 1),2) Politeknik Kesehatan Tasikmalaya Program Studi Kebidanan Cirebon \\ E-mail : asihh1178@gmail.com
}

\begin{abstract}
In Indonesia, Yoga is currently one of the most popular sports, not only for the general public but also for pregnant women. Many benefits can be obtained from prenatal yoga including the mother feeling comfortable and relaxed throughout pregnancy and during childbirth, training the pelvic floor muscles and perineum, keeping the body's muscles relaxed, balanced during childbirth, reducing stress, increasing and improving oxygen circulation to the body and fetus. . This study aims to determine the effect of prenatal yoga on optimizing fetal position on third trimester Primigravida maternal delivery output at Puskesmas Cirebon City. This research is a quasi-experimental research pre post control group design and only post control group design with $T$ test and Chi Square test. Paired T Test results of the intervention group (mean difference $=3.111, P$ value $=0.000$, control group (mean difference $=0.833, P$ value $=0.318$ ). Independent $T$ Test results obtained (average difference $=-1.944, P$ value $=0.024$ ), Chi Square test obtained a value of $P=0.73$. There is a difference in the average anxiety before and after the intervention in the intervention group, there is no difference in average anxiety before and after the intervention in the control group. There is a difference in the average anxiety between the intervention and control groups. There is a difference in mean Long I stage between the intervention and control groups There was no effect of prenatal yoga on the type of labor
\end{abstract}

Keywords: Prenatal Yoga; Labor Output.

\begin{abstract}
ABSTRAK
Di Indonesia saat ini senam Yoga menjadi salah satu olahraga yang digemari, tidak hanya masyarakat umum tapi juga oleh ibu hamil. Banyak manfaat dapat diperoleh dari yoga prenatal diantaranya ibu merasa nyaman dan rileks sepanjang kehamilan dan saat melahirkan, melatih otot-otot dasar panggul serta perineum, menjaga otot tubuh tetap rileks, seimbang saat melahirkan, mengurangi stress, meningkatkan serta melancarkan peredaran oksigen ke tubuh maupun janin. Penelitian ini bertujuan mengetahui pengaruh prenatal yoga optimalisasi posisi janin terhadap output persalinan Ibu Primigravida Trimester tiga di

Cara mengutip: Nurasih \& Nurrochmi, Endang. (2020). Optimalisasi posisi janin melalui prenatal yoga terhadap output persalinan di Puskesmas Wilayah Kota Cirebon. Care:Jurnal Ilmiah Ilmu Kesehatan, 8(3), 396-407

Retrieved from https://jurnal.unitri.ac.id/index.php/care/article/view/1816
\end{abstract}


Puskesmas Wilayah Kota Cirebon. Penelitian ini merupkan penelitian quasi eksperimen pre post control group design dan only post control group design dengan uji $\mathrm{T}$ dan uji Chi Square. Hasil uji Paired T Tes kelompok intervensi (beda rerata $=3.111$, nilai $\mathrm{P}=0.000$, kelompok kontrol (beda rerata $=0.833$, nilai $\mathrm{P}=0.318$ ). Uji independen $\mathrm{T}$ Tes diperoleh hasil (beda rata-rata $=-1.944$, nilai $\mathrm{P}=0.024$ ), Uji Chi Square diperoleh nilai $\mathrm{P}=0.73$. Terdapat perbedaan rerata kecemasan sebelum dan setelah intervensi pada kelompok intervensi, tidak terdapat perbedaan rerata kecemasan sebelum maupun setelah intervensi pada kelompok kontrol.Terdapat perbedaan rerata kecemasan antara kelompok intervensi dan kontrol.Terdapat perbedaan rerata Lama Kala I antara kelompok intervensi dan kontrol. Tidak ada pengaruh Yoga prenatal terhadap Jenis persalinan.

Kata Kunci : Yoga Prenatal; Output Persalinan.

\section{PENDAHULUAN}

Proses persalinan merupakan proses yang penuh kejutan. Kita tidak bisa selalu memastikan proses persalinan berjalan dengan lancar maupun nyaman karena kemungkinan apapun bisa terjadi selama proses persalinan. Persalinan merupakan hal paling dinantikan sekaligus merupakan bayangan menakutkan untuk seorang ibu terutama pada ibu primigravida yang menyebabkan rasa nyeri dialami saat proses persalinan lebih lama sehingga risiko mengalami keletihan lebih besar yang tentunya berakibat pada respon emosi berupa cemas, tegang, takut maupun panik. Beradasarkan kondisi tersebut perlu dilakukan prenatal care ibu hamil dengan tujuan persalinan yang fisiologis, ibu dan anak sehat. Keadaan ini dicapai melalui bantuan wanita hamil itu sendiri melalui ketenangan serta relaksasi tubuh sempurna. Intervensi dapat dilakukan oleh ibu selama kehamilan adalah dengan mengikuti latihan fisik seperti Prenatal Yoga. Prenatal Yoga merupakan olah raga atau latihan fisik yang berfungsi untuk mempersiapkan persalinan karena teknik latihannya menitikberatkan pada kelenturan otot jalan lahir, teknik pernapasan, relaksasi, dan ketenangan pikiran ibu selama mengahadapi proses persalinan. Diketahui banyak manfaat yang didapatkan dalam Prenatal Yoga terhadap proses persalinan yaitu kesiapan fisik dan psikologi pada ibu hamil, mengurangi rasa cemas selama kehamilan dan proses persalinan, meningkatkan kualitas tidur, mengurangi nyeri saat persalinan, mempercepat persalinan kala I, mempercepat persalinan kala II, dan membuat persalinan normal tanpa komplikasi (Negari \& Christiani, 2017).

Faktor psikologis mempunyai pengaruh terhadap terjadinya gangguan saat proses persalinan. Kejadian persalinan lama sekitar 65\% disebabkan karena kontraksi 
uterus yang tidak efisien, adanya disfungsional kontraksi uterus sebagai respon terhadap kecemasan sehingga menghambat aktifitas uterus. Respon tersebut merupakan bagian dari komponen psikologis, sehingga dapat dinyatakan bahwa besar pengaruh faktor psikologis dalam keselamatan menjelang persalinan pada ibu (Rusmita, 2011) sitasi (Wulandari, Retnaningsih, \& Aliyah, 2018).

Penelitian sebelumnya yang membuktikan bahwa yoga sangat bermanfaat bagi ibu hamil, menurut penelitian (Wulandari et al., 2018) tentang pengaruh Prenatal Yoga terhadap tingkat kecemasan pada ibu primigravida trimester II dan III di studio Qita Yoga Semarang mendapatkan hasil ada pengaruh Prenatal Yoga terhadap tingkat kecemasan ibu primigravida trimester II dan III. Penelitian (Amalia Riza, 2014) tentang perbedaan senam hamil dan Prenatal Yoga terhadap kesemasan diperoleh hasil yoga prenatal lebih efektif menurunkan tingkat kecemasan dibandingkan dengan senam hamil.

Sementara itu (Dewi, Suwondo, \& Wahyuni, 2016) dalam penelitiannya tentang pengaruh Kombinasi Yoga Prenatal dan Senam Hamil terhadap
Perubahan Kadar Kortisol dan Lama Persalinan Kala I diperoleh hasil bahwa ada pengaruh kombinasi yoga prenatal dan senam hamil terhadap lama persalinan kala I. Penelitian lain tentang efektifitas Prenatal Yoga dan senam hamil pada primi gravida terhadap durasi persalinan didapatkan hasil bahwa Prenatal Yoga lebih efektif daripada senam hamil dalam mempersingkat durasi persalinan normal (Linda, Lubis, \& Siregar, 2017). Sementara itu Sarwendah (2015) dalam penelitiannya mendapatkan hasil bahwa ibu yang mengalami proses persalinan spontan lebih berpeluang terjadi pada ibu yang melakukan yoga prenatal secara teratur dibandingkan ibu yang melakukan yoga prenatal secara tidak teratur (Negari \& Christiani, 2017).

Kegiatan kelas Ibu Hamil telah berjalan di Puskesmas wilayah Kota Cirebon sebagai upaya yang dilakukan untuk meningkatkan kesehatan Ibu hamil namun belum menyentuh pada kegiatan Yoga Prenatal, dan berdasarkan penelitian-penelitian tentang Prenatal Yoga yang telah dilakukan peneliti sebelumnya, pada penelitian ini peneliti memberikan intervensi dengan menambahkan gerakan yang memberikan manfaat pada optimalisasi posisi janin 
pada kelompok intervensi untuk melihat pengaruhnya terhadap out put persalinan.

\section{METODE PENELITIAN}

Penelitian ini merupakan penelitian kuasi eksperimental melalui pemberian intervensi berupa Prenatal Yoga dengan pre post control group desain untuk variabel kecemasan dan only post control group desain untuk variabel lamanya kala I dan jenis persalinan. Penelitian ini dilakukan di Puskesmas Wilayah Dinas Kesehatan Kota Cirebon baik untuk kelompok intervensi maupun kelompok kontrol meliputi Puskesmas Sunyaragi, Majasem, Jagasatru, Pamitran dan Kejaksan. Sampel dalam penelitian ini terdiri dari sampel kelompok intervensi dan kontrol, yang memenuhi kriteria inklusi dan eksklusi. Adapun kriteria inklusinya adalah hamil trimester III, primigravida, dan bersedia menjadi responden. Sedangkan kriteria eksklusinya adalah ibu hamil dengan penyulit (placenta previa, kontraksi premature), maupun ibu dengan rencana SC. Sampel kelompok intervensi adalah kelompok perlakuan yang diberikan latihan Prenatal Yoga dengan optimalisasi posisi janin dan sampel kontrol adalah kelompok perlakuan yang hanya diberikan latihan senam hamil. Pengambilan sampel dilakukan secara purposive sampel. Besar sampel dalam penelitian ini menggunakan rumus perbedaann rata dua populasi satu arah (Lameshow at al, 1997). Perhitungan besar sampel pada penelitian ini merujuk pada penelitian (Dewi et al., 2016). Berdasarkan perhitungan besar sampel maka diproleh sampel : 17. Jumlah seluruh sampel pada penelitian ini sebanyak 36 terbagi menjadi masingmasing 18 responden pada kelompok intervensi maupun kelompok kontrol. Variabel independen berupa Prenatal Yoga dengan Optimalisasi posisi janin dan independen yaitu out put persalinan yang terdiri dari Lamanya kala I, Jenis Persalinan dan Tingkat Kecemasan. Sedangkan hipotesis dalam penelitian ini adalah Prenatal Yoga dengan optimalisasi posisi janin lebih berpengaruh terhadap output persalinan dibandingkan dengan Senam Hamil.

Pengumpulan data berupa data primer yang diambil langsung dari responden. Dalam pengumpulan data selain dilakukan oleh peneliti sendiri juga dibantu oleh bidan PONED dan Puskesmas wilayah Dinas Kota Cirebon. Instrumen yang digunakan dalam penelitian ini berupa kuesioner untuk menilai tingkat kecemasan (skala HARS) serta lembar observasi berupa Parthograf untuk melihat lama kala I dan jenis 
persalinan responden. Analisis data dalam penelitian ini menggunakan analisis univariat, dan bivariat. Analisis bivariat untuk menilai pengaruh kecemasan sebelum dan sesudah serta lamanya kala I pada kelompok intervensi dan kontrol menggunakan uji paired $T$ test, sedangkan untuk membandingkan pengaruh yoga prenatal dengan optimalisasi posisi janin dan Senam Hamil menggunakan uji independen $T$ test. Sementara itu untuk melihat hubungan antara intervensi terhadap jenis persalinan menggunakan uji Chi Square.

\section{HASIL}

Data dalam penelitian ini yang berbentuk data numerik telah dilakukan uji normalitas data. Dan karena jumlah sampel kurang dari 50 maka uji normalitas data untuk melihat apakah data berdistribusi normal atau tidak dilakukan dengan uji Shapiro-Wilk. Hasil uji normalitas data diperoleh nilai $\mathrm{P}$ $(>0.05)$, sehingga dapat dikatakan bahwa data berdistribusi normal.

Tabel 1. Gambaran Jenis Persalinan Responden

\begin{tabular}{|c|c|c|}
\hline Jenis Persalinan & $\mathrm{N}$ & $(\%)$ \\
\hline Normal & 19 & 52.8 \\
\hline SC & 17 & 47.2 \\
\hline
\end{tabular}

Hasil penelitian yang tampak pada tabel 1 diperoleh bahwa mayoritas responden dengan jenis persalinan normal (52.8\%).

Tabel 2. Rata-rata Skala Kecemasan sebelum dan sesudah perlakuan pada Kelompok Intervensi dan Kelompok Kontrol

\begin{tabular}{clccccc}
\hline Metode & \multicolumn{1}{c}{ Variabel } & Rerata & SD & SE & Min-Max & CI 95\% \\
\hline \multirow{5}{*}{ Intervensi } & Cemas Pre & 12.28 & 5.582 & 1.316 & $4-21$ & $\begin{array}{c}9.50- \\
15.05\end{array}$ \\
\cline { 2 - 6 } & Cemas Post & 9.17 & 4.630 & 1.091 & $2-18$ & $\begin{array}{c}6.86- \\
11.47\end{array}$ \\
\cline { 2 - 6 } & Lama Kala I & 6.611 & 2.8105 & 0.6624 & $3.0-12$ & $\begin{array}{c}5.214- \\
8.009\end{array}$ \\
\hline \multirow{3}{*}{ Kontrol } & Cemas Pre & 13.39 & 6.232 & 1.469 & $6-30$ & $\begin{array}{c}10.29- \\
16.49\end{array}$ \\
\cline { 2 - 6 } & Cemas Post & 12.56 & 8.198 & 1.932 & $3-31$ & $\begin{array}{c}8.48- \\
16.63\end{array}$ \\
\cline { 2 - 7 } & Lama Kala I & 8.500 & 1.9478 & 0.4591 & $5.0-12.0$ & $\begin{array}{c}7.531- \\
7.531\end{array}$ \\
\hline
\end{tabular}

Berdasarkan Tabel 2 diperoleh hasil bahwa pada kelompok intervensi (yoga) rata-rata kecemasan sebelum 12.28 dan setelah 9.17, dengan nilai min - $\max 4-$
21 dan 2 - 18, CI $9.50-15.05$ dan $6.86-$ 11.47, sedangkan berdasarkan Tabel 3 menunjukkan rerata kecemasan sebelum intervensi pada kelompok Yoga sebesar 
12.28 dan rerata setelah intervensi sebesar

9.17 dengan beda rerata 3.111 .

Tabel 3. Uji Paired T Test Beda Rerata Skala Kecemasan Responden pada Kelompok Intervensi dan Kelompok Kontrol

\begin{tabular}{|c|c|c|c|c|c|}
\hline Kelompok & Variabel & Rerata & Beda Rerata & CI $95 \%$ & P Value \\
\hline Intervensi & $\begin{array}{l}\text { Cemas } \\
\text { Pre } \\
\text { Cemas } \\
\text { Post }\end{array}$ & $\begin{array}{l}12.28 \\
9.17\end{array}$ & 3.111 & $\begin{array}{c}2.047- \\
4.175\end{array}$ & 0.000 \\
\hline Kontrol & $\begin{array}{l}\text { Cemas } \\
\text { Pre } \\
\text { Cemas Post }\end{array}$ & $\begin{array}{l}13.39 \\
12.56\end{array}$ & 0.833 & $\begin{array}{c}-0.874- \\
2.541\end{array}$ & 0.318 \\
\hline
\end{tabular}

Tabel 4 menunjukkan perubahan rerata kecemasan responden sebelum dan setelah intervensi pada kelompok Yoga prenatal sebesar -3.11, sedangkan pada kelompok senam hamil sebasar -1.17. Beda rerata antara kedua kelompok sebesar -1.944 dengan $\mathrm{P}$ value sebesar 0.024. Hal ini menunjukkan bahwa terdapat perbedaan yang signifikan pada rerata kecemasan. Sementara itu perubahan rerata Lama Kala I yang dialami responden pada kelompok Yoga prenatal sebesar 6.611 dan 8.500 pada kelompok Senam hamil. Beda rerata antara kedua kelompok sebesar -1.8889 dengan $\mathrm{P}$ value 0.025 . Hal tersebut menunjukkan bahwa terdapat perbedaan yang signifikan pada rerata Lama Kala I.

Tabel 4. Uji independen $\mathrm{T}$ Test Beda Rerata Yoga dengan Optimalisasi Posisi Janin terhadap Skala Kecemasan dan Lama Kala I

\begin{tabular}{lccccc}
\hline \multicolumn{1}{c}{ Variabel } & Rerata & $\begin{array}{c}\text { Beda } \\
\text { Rerata }\end{array}$ & SD & CI 95\% & P value \\
\hline Cemas & & & & & \\
\hline Intervensi & -3.11 & -1.944 & $\begin{array}{c}2.139 \\
2.749\end{array}$ & $\begin{array}{c}-3.613-- \\
0.276\end{array}$ & 0.024 \\
Kontrol & -1.17 & & & & \\
\hline Lama & & & & & 0.025 \\
Kala I & & & & & \\
\hline Intervensi & 6.611 & -1.8889 & 2.8105 & $-3.5268-$ & \\
Kontrol & 8.500 & & 1.9478 & -0.2509 & \\
\hline
\end{tabular}

Hasil Uji Chi Square yang tampak pada tabel 5 diperoleh P value sebesar 0.73 (.> 0.05), sehingga dapat disimpulkan bahwa Tabel 5

Uji Chi Square Prenatal Yoga dengan Optimalisasi Posisi Janin Terhadap Jenis Persalinan yoga prenatal dengan optimalisasi posisi janin tidak berpengaruh terhadap jenis persalinan. 


\begin{tabular}{|c|c|c|c|c|c|c|c|}
\hline \multirow{3}{*}{ Kelompok } & \multicolumn{4}{|c|}{ Jenis Persalinan } & \multirow{2}{*}{\multicolumn{2}{|c|}{ Total }} & \multirow{3}{*}{ P Value } \\
\hline & \multicolumn{2}{|c|}{ Normal } & \multicolumn{2}{|c|}{ SC } & & & \\
\hline & $\mathrm{n}$ & $\%$ & $\mathrm{n}$ & $\%$ & $\mathrm{n}$ & $\%$ & \\
\hline Intervensi & 10 & 55.6 & 8 & 44.4 & 18 & 100 & 073 \\
\hline Kontrol & 9 & 50 & 9 & 50 & 18 & 100 & \\
\hline
\end{tabular}

\section{PEMBAHASAN}

Hasil penelitian yang tampak pada tabel 1 diperoleh bahwa mayoritas responden dengan jenis persalinan normal (52.8\%). Responden dengan persalinan normal lebih banyak jumlahnya dengan responden dengan persalinan SC meskipun perbandingannya tidak begitu besar. Hal ini sesuai dengan teori yang menyatakan bahwa wanita hamil yang melakukan yoga secara rutin akan memperoleh keuntungan yaitu memperlancar proses persalinan, mengurangi tindakan SC, dan mengurangi terjadinya gawat janin pada waktu persalinan (Negari \& Christiani, 2017).

Tabel 2 menunjukkan hasil bahwa pada kelompok intervensi rata-rata kecemasan sebelum 12.28 dan setelah 9.17 . Sedangkan pada kelompok kontrol diperoleh rata-rata kecemasan sebelum 13.39 dan setelah 12.56. Hasil penelitian ini dapat disimpulkan bahwa pada masing-masing kelompok baik yoga maupun senam hamil terlihat penurunan kecemasan sebelum dan sesudah intervensi, dengan lama kala I pada kelompok Yoga berlangsung 6.6 jam sedangkan pada kelompok senam hamil 8.5 jam. Pada primigravida fase aktif yang lebih panjang dari 12 jam merupkan keadaan abnormal. Yang lebih penting daripada fase ini adalah kecepatan dilatasi serviks. Laju yang kurang dari $1.2 \mathrm{~cm}$ perjam membuktikan adanya abnormalitas. Pemanjangan fase aktif menyertai kondisi seperti mal posisi janin, disproporsi cephalopelvik, penggunaan sedative dan analgetik berlebihan, dan ketuban pecah dini sebelum dimulainya persalinan.

\section{Perbedaan rerata Kecemasan sebelum} dan setelah intervensi pada kelompok Yoga prenatal dan Kelompok Senam

\section{Hamil}

Pengkuran kecemasan pada responden terhadap kedua kelompok intervensi penelitian ini dilakukan dua kali yaitu sebelum dilakukan intervensi dan setelah intervensi yang terakhir, dimana pada penelitian ini intervensi dilakukan pada kedua kelompok sebanyak dua kali dalam seminggu dan dilakukan selama tiga 
minggu dengan lama intervensi 60 menit pada masing-masing kelompok.

Tabel 3 menunjukkan rerata kecemasan sebelum intervensi pada kelompok intervensi sebesar 12.28 dan rerata kecemasan setelah intervensi sebesar 9.17 dengan beda rerata 3.111 . Berdasarkan $P$ value 0.000 maka terdapat perbedaan secara siginfikan kecemasan sebelum dan setelah intervensi pada kelompok internensi, sehingga dapat diartikan bahwa terdapat penurunan kecemasan yang berarti secara statistik pada kelompok intervensi. Hal ini sesuai dengan yang disampaikan oleh (Sindhu Pujiastuti, 2014) bahwa yoga prenatal memberikan pengaruh terhadap penurunan tingkat kecemasan. Sementara itu pada kelompok kontrol, didapatkan hasil rerata kecemasan sebelum intervensi sebesar 13.39 dan rerata kecemasan setelah intervensi sebesar 12.56 dengan beda rerata sebesar 0.833. Berdasarkan $\mathrm{P}$ value sebasar 0.318 , maka tidak terdapat perbedaan yang signifikan kecemasan sebelum dan setelah intervensi pada kelompok kontrol. Hal ini dapat dikatakan bahwa senam hamil sangat kecil perannya secara statistik dalam menurunkan kecemasan.
Berlatih yoga prenatal selain bermanfaat untuk mengolah fisik juga bermanfaat untuk mengolah pikiran dan hati agar ibu hamil senantiasa merasa tenang dan tentram, selain itu juga meningkatkan kemampuan ibu hamil untuk memusatkan perhatian agar dapat berkonsentrasi dan berkomunikasi dengan bayinya. Hal ini sesuai dengan penelitian Jenifer (2012) bahwa yoga merupakan alternatif perlakuan untuk ibu hamil yang mengalami tingkat kecemasan. Yoga tidak hanya menurunkan tingkat kecemasan, namun juga menekan beberapa gejala vegetatif timbulnya tingkat kecemasan (Amalia Riza, 2014). Selain itu juga didalam yoga prenatal ibu hamil diajak untuk benar-benar fokus pada tubuhnya sendiri, dan apabila ibu tidak fokus maka beberapa gerakan akan terganggu dalam hal keseimbangan. Pada pelaksanaan yoga prenatal pada awal sesi dimulai dengan centering (pemusatan perhatian), pranayama (latihan pernafasan), pemanasan, gerakan inti dan diakhiri dengan savasana (posisi mayat) ibu dalam posisi rileks dan tenang yang merupakan saat yang paling tepat untuk menjalin hubungan ibu dan janin dalam kandungan (Suananda Yhossie, 2017).

Tiga komponen inti dalam senam hamil terdiri dari latihan pernafasan, latihan penguatan dan peregangan otot, serta 
latihan relaksasi. Ketiganya memiliki pengaruh yang berbeda terhadap kondisi ibu hamil. Saat ibu hamil melakukan pernafasan, khususnya pernafasan dalam, mereka merasakan nafasnya menjadi teratur, ringan, tidak tergesa-gesa, serta panjang. Disamping itu latihan penguatan dan peregangan otot juga berdampak pada berkurangnya ketegangan ibu hamil. Diakhir program senam hamil, terdapat latihan relaksasi yang menggabungkan antara relaksasi otot dan relaksasi pernafasan. Pada latihan ini, ibu hamil melakukannya sambil membayangkan keadaan bayi didalam kandungan dalam kondisi baik-baik saja. Hal ini cukup membawa pengaruh relaksasi pada ibu hamil (Amalia Riza, 2014).

\section{Beda Rerata Yoga prenatal dengan optimalisasi Posisi Janin terhadap}

\section{Kecemasan dan Lama Kala I}

Tabel 4 menunjukkan perubahan rerata kecemasan responden sebelum dan setelah intervensi pada kelompok intervensi sebesar -3.11, sedangkan pada kelompok control sebesar -1.17. Beda rerata antara kedua kelompok sebesar 1.944 dengan P value sebesar 0.024. Hal ini menunjukkan bahwa terdapat perbedaan yang signifikan pada rerata kecemasan pada kelompok intervensi dibandingkan dengan kontrol. Dapat diartikan bahwa yoga prenatal lebih efektif menurunkan kecemasan dibandingkan dengan senam hamil.

Brown et al (2005) sitasi (Negari \& Christiani, 2017) menyatakan bahwa yoga merupakan suatu metode yang unik untuk menyeimbangkan sistem syaraf otonom dan memberikan pengaruh pada gangguan fisik dan gangguan yang berhubungan dengan stres. Teknik pernafasan yoga menyebabkan terjadinya peningkatan kerja parasimpatis, memberikan efek tenang, merangsang pelepasan oksitosin dan disebutkan pula bahwa dengan latihan pernafasan yoga selama tiga minggu menyebabkan penurunan produksi hormon kortisol yang signifikan. Hasil penelitian Kathryn (2012) sitasi (Amalia Riza, 2014) menyatakan bahwa yoga akan membantu ibu hamil dalam mengelola tingkat kecemasan. Dalam yoga diajarkan bagaimana proses pernafasan yang ritmis serta menikmati aliran nafas dalam tubuh sehingga sistem syaraf parasimpatis menstimulasi turunnya semua fungsi yang dinaikkan oleh sistem syaraf simpatis. Maka relaksasi dapat menekan rasa tegang dan cemas. Hasil penelitian ini selaras dengan penelitian (Amalia Riza, 2014) yang menyatakan bahwa terdapat perbedaan senam hamil dan yoga prenatal 
terhadap tingkat kecemasan responden, dimana yoga prenatal lebih efektif menurunkan tingkat kecemasan dibandingkan dengan senam hamil.

Hasil analisis terkait lama kala I pada tabel 4 didapatkan hasil terdapat perubahan rerata Lama Kala I yang dialami responden pada kelompok intervensi sebesar 6.611 dan 8.500 pada kelompok kontrol. Beda rerata antara kedua kelompok sebesar -1.8889 dengan $\mathrm{P}$ value 0.025 . Hal tersebut menunjukkan bahwa terdapat perbedaan yang signifikan pada rerata lama kala I. sehingga dapat disimpulkan bahwa Yoga prenatal dapat mempersingkat lama kala I persalinan di bandingkan dengan senam hamil.

Hasil penelitian ini sejalan dengan penelitian (Eni, Devi, Sulastriningsih, \& Tiawaningrum, 2018) yang menyatakan bahwa ada pengaruh yoga prenatal terhadap kala I persalinan. Lama kala I persalinan pada ibu hamil yang melalukan yoga lebih singkat dimungkinkan karena adanya latihan olah nafas dan latihan olah tubuh yang dapat berpengaruh terhadap power, passanger, passage dan pskologis ibu bersalin.

Perbedaan kemajuan persalinan pada ibu primigravida salah satunya disebabkan oleh kesiapan ibu dalam menghadapi persalinan. Stres yang dialami ibu bersalin dapat menghambat kemajuan persalinan. Kecemasan, ketakutan dan rasa nyeri merupakan salah satu perasaan yang dialami ibu bersalin saat memasuki masa persalinan. Telah diketahui bahwa Yoga pada ibu hamil merupakan salah satu jenis rangkaian gerakan tubuh yang dipadukan dengan rileksasi pikiran dan menguatkan mental dalam menghadapi proses melahirkan. Gerakan yoga terdiri dari pernafasan yang dapat digunakan sebagai media rileksasi ibu sehingga dapat merasakan kenyamanan selama proses persalinan. Pernafasan yang dilakukan dengan cara nafas secara dalam dapat meningkatkan kontraksi uterus yang dapat menghasilkan tekanan pada dinding uterus, sehingga pada saat tekanan tersebut disalurkan ke serviks dapat mengakibatkan penipisan dan dilatasi pada serviks.

\section{Pengaruh Yoga Preanatal terhadap Jenis Persalinan.}

Tabel 5 Hasil uji Chi Square Yoga Prenatal terhadap Jenis Persalinan diperoleh $\mathrm{P}$ value 0.73 lebih besar dari $\alpha(0.05)$ maka dapat disimpulkan tidak terdapat pengaruh Yoga prenatal terhadap jenis persalinan. Telah diketahui bahwa secara teori Hasil penelitian ini berbeda dengan penelitian yang dilakukan oleh Dian 
Sarwenah (2015) yang menyatakan bahwa ibu yang mengalami proses persalinan spontan lebih berpeluang terjadi pada ibu yang melakukan yoga prenatal secara teratur dibandingkan dengan ibu yang melakukan yoga prenatal secara tidak teratur. Hasil penelitian ini juga bertolak belakang dengan teori yang dikemukakan oleh Wiadyana (2008) sitasi (Negari \& Christiani, 2017) yang menyatakan bahwa wanita hamil yang melakukan yoga prenatal secara rutin akan memeproleh keuntungan yaitu memperlancar proses persalinan, mengurangi tindakan secsio caesarea, dan mengurangi terjadinya gawat janin pada waktu persalinan. Perbedaan hasil penelitian ini dimungkinan karena secara teori telah diketaui bahwa proses persalinan dipengaruhi oleh 5 faktor yaitu power, passage, pasanger, penolong dan psikis. Apabila salah satu dari faktor tersebut mengalami kelainan, misalnya keadaan yang menyebabkan kekuatan his menjadi tidak adekuat, kelainan pada bayi atau kelainan jalan lahir maka persalinan tidak dapat berjalan secara normal (Negari \& Christiani, 2017).

\section{KESIMPULAN}

Sebagian besar responden jenis persalinan normal, rata-rata kecemasan kelompok intervensi sebelum 12.28 dan sesudah 9.17. Kelompok kontrol rata-rata kecemasan sebelum 13.39 dan sesudah 12.56, rata-rata lama Kala I kelompok intervensi 6 jam, sedangkan kelompok control 8 jam, terdapat perbedaan rerata kecemasan sebelum dan setelah intervensi pada kelompok intervensi (Yoga). Tidak terdapat perbedaan rerata kecemasan sebelum dan setelah intervensi pada kelompok kontrol (senam), terdapat perbedaan rerata Kecemasan antara kelompok intervensi dan control, terdapat perbedaan rerata Lama Kala I antara kelompok intervensi dan control, dan tidak terdapat pengaruh Yoga dengan optimalisasi janin terhadap Jenis persalinan.

\section{UCAPAN TERIMA KASIH}

Terima kasih kepada Poltekkes Kemenkes Tasikmalaya atas dukungan dana terhadap penyelengaraan kegiatan penelitian, dan Kepala Dinas Kesehatan Kota Cirebon, Kepala Puskesmas serta Bidan Koordinator di tempat penelitian atas izinnya sehingga penelitian ini dapat terlaksana.

\section{REFERENSI}

Amalia Riza. (2014). The Difference Between Pregnancy Gymnastics and Prenatal Yoga Treatment Toward 
Pregnant Mother Anxiousness Grade In Third Trimester In Pregnant Mother Class, Unggaran Public Health Center Work Area, Semarang Regency.

Amrin Muchlish Ahmad. (2010). Kiat-kiat Melabirkan Tanpa Rasa Sakit yang Menakutkan. (H. R. Evi, Ed.) (Pertama). Jogjakarta: Garailmu.

Aprilia Yesie. (2017). Bebas Takut Hamil dan Melabirkan. Jakarta: PT Gramedia Pustaka Utama.

Dewi, E. S., Suwondo, A., \& Wahyuni, S. (2016). Pengaruh Kombinasi Yoga Prenatal dan Senam Hamil terhadap Perubahan Kadar Kortisol dan Lama Persalinan Kala I. Jurnal Imiah Bidan, Vol I(3), 7-13.

Eni, T., Devi, R., Sulastriningsih, K., \& Tiawaningrum, E. (2018). pISSN 2477-3441 eISSN 2477-345X Pengaruh Yoga Prenatal dan Hypnobirthing terhadap proses Persalinan Kala I pada Ibu Bersalin di BPM Restu Depok Periode Januari-Juni Tahun 2017 The Influence Of Hypnobirthing and Yoga on Labor Process on One on Mother Labor, 5(01), 26-32.

Fatmawati Diana. (2017). Pengaruh Yoga pada Ibu Inpartu Primigravida terhadap Kemajuan Persalinan Kala I fase Aktif. Jurnal Ners Dan Kebidanan, volume 4 N, 3539.https://doi.org/10.26699/jnk.v4i 1.ART.p035-039

Fauziah Siti. (2015). Keperawatan Maternitas Volume 2 Persalinan (Pertama).
Jakarta.

Irianti Bayu, Halida Mutiara Elda, Duhita Fitria, P. F. (2014). Asuban Kehamilan Berbasis Bukti. (Husin Farid, Ed.) (Ke-1). Jakarta: Sagung Seto.

Linda, I., Lubis, R., \& Siregar, Y. (2017). Effectiveness of Physical Exercise , Prenatal Yoga and Pregnancy Gymnastics in Primigravida on Childbirth Duration, 1(2), 113-117.

Maryunani Anik. (2010). Nyeri dalam Persalinan Teknik dan Cara Penanganannya (Pertama). Jakarta.

Negari, K. W., \& Christiani, N. (2017). Manfaat Prenatal Yoga terhadap Proses Persalinan (pp. 305-310). Ngudi Waluyo.

Nirvikalpa Yoga Indonesia. (2017). Manual Book Yoga For Senior Teacher Training. Bandung.

Notoatmodjo, S. (2005). Metodologi Penelitian Kesehatan. Jakarta: Rineka Cipta.

Sindhu Pujiastuti. (2014). Yoga untuk Kehamilan. Bandung: Qanita.

Suananda Yhossie. (2017). Prenatal Postnatal Yoga. (T. Merwin, Ed.) (ke 1). Jakarta: Rafikatama.

Worby Cyntia. (n.d.). Memahami Segalanya Tentang Yoga. (W. Istiono, Ed.). Tangerang: Kharisma Publishing Group.

Wulandari, P., Retnaningsih, D., \& Aliyah, E. (2018). The Effect of Prenatal Yoga on Primigravida Trimester II and III in Studio Qita Yoga District South Semarang Indonesia, 9, 25-34. 